\title{
Formation Mechanism of Knowledge Stickiness in the Collaborative Innovation of Industry-University-Research
}

\author{
Feng ZHANG, Guoxin LIU*, Yu WU
}

\begin{abstract}
In the context of deepening the cooperation of Industry-University-Research (IUR), enterprises must gain competitive advantage by transferring external knowledge to the enterprise for knowledge appreciation. Based on the knowledge stickiness encountered in the process of knowledge transfer in the collaborative innovation of IUR, the formation process and causes of knowledge stickiness are analyzed. In this study, the knowledge flow model based on heat conduction theory was proposed. The dynamic simulation was carried out using MATLAB software. Results show that the process of knowledge transfer between IUR is the process of continuously realizing knowledge increment and knowledge creation, and knowledge stickiness has a direct impact on the efficiency of knowledge transfer. Strengthening the cognition between IUR, increasing the number of activities between IUR, and creating a collaborative innovation atmosphere between IUR will reduce knowledge stickiness and improve the efficiency of knowledge transfer.
\end{abstract}

Keywords: collaborative innovation; industry-university-research (IUR); knowledge stickiness

\section{INTRODUCTION}

Collaborative innovation, as an important form in the development of innovation system, continues to promote the development of scientific and technological innovation activities in the era of knowledge economy [1]. By using the cooperative mechanism between technological innovation subject and knowledge creation subject [2-5], enterprises, universities, and scientific research institutes can realize the cooperative effect among different subjects $(n+n>2 n)$ and the cooperative creation within a single subject $(1+1>2)$.

Knowledge collaboration is the core of IUR collaborative innovation and the core transmission process [6]. Moreover, knowledge collaboration improves the transformation rate of scientific and technological achievements of universities and the efficiency of enterprises [7]. However, not all knowledge can be transferred effectively. Ineffective mode, poor mechanism, insufficient motivation [8] and tacit knowledge hinder the transfer of knowledge between IUR [9], resulting in knowledge stickiness [10]. Many cooperation projects between IUR fail because for these organizations, reducing the knowledge stickiness effect is the key to realize the collaborative innovation of IUR in the face of difficult or high cost of knowledge transfer. In this case, fully understanding the problem of knowledge stickiness will be conducive to improving the performance of knowledge transfer [11, 12]. Furthermore, analyzing the causes of knowledge stickiness from the internal mechanism and weakening the transfer measures will be the key to achieve collaborative innovation and will have practical significance on the effective development of scientific and technological achievements transformation in IUR [13]. Although domestic and foreign scholars have rich research results on the mechanism of collaborative innovation and knowledge management (sharing, transfer), few studies have combined them to study the knowledge stickiness of IUR collaborative innovation.

Thus, this study focuses on the cause and process of knowledge stickiness in the context of collaborative innovation of IUR. On the micro level and based on the perspective of S-A-C, the analysis framework of the influencing factors of knowledge stickiness is put forward. In addition, the internal influence mechanism of knowledge stickiness is analyzed from the three levels of situation, activity, and cognition. On the macro level and based on heat conduction theory, the evolution process of knowledge transfer stickiness is simulated dynamically, the evolution rule of knowledge stickiness in the collaborative environment of IUR is analysed. Through the study of knowledge stickiness mechanism, it is effective to provide reference for the innovation practice between IUR, the countermeasures put forward to weaken knowledge stickiness are significant to promote the smooth flow and sharing of knowledge, as well as to improve the cooperation efficiency, which can be used to solve the problem of knowledge stickiness between IUR in reality.

\section{RELATED WORKS}

\subsection{Connotation of Knowledge Stickiness}

Von Hipple [10] first proposed the concept of "sticky information". He believed that the process of knowledge acquisition or knowledge transfer entailed cost, and information stickiness was directly proportional to the cost. Szulanski [14] \& Simonin [15] put forward the concepts of "internal viscosity" and "knowledge fuzziness", respectively. From then on, scholars began paying attention to "knowledge stickiness" and carried out numerous researches. The local definitions of knowledge stickiness are mainly cost theory and knowledge theory. Cost theory refers to the difficulty of knowledge flow and the cost of knowledge transfer, mainly discussing the cost or price of knowledge in the process of transfer. Moreover, knowledge theory refers to knowledge that is difficult to be transferred or applied, mainly discussing that knowledge itself cannot be transferred. This study holds that knowledge stickiness describes the obstruction or stagnation of knowledge in the process of transferring, sharing, or regenerating [16-17]. The "knowledge stickiness coefficient" can be used to express the difficulty and cost of knowledge transfer. The greater the knowledge stickiness coefficient, the greater the difficulty and cost of knowledge transfer, and vice versa. 


\subsection{Influencing Factors of Knowledge Stickiness}

Factors that affect knowledge stickiness include subjective factors, such as knowledge source and knowledge receptor [18], and objective factors, such as knowledge characteristics and situation $[19,20]$. Researchers have different analyses on the causes of knowledge stickiness from different perspectives. Szulanski [21] thought that knowledge stickiness was affected by knowledge characteristics, knowledge sources, knowledge receptors, and transfer situations. Cummings and Teng [22] pointed out that the key factors affecting the success of knowledge transfer include the expressiveness and embeddedness of knowledge, knowledge distance, project priority, and transfer activities. Pérez-Nordtvedt et al. [23] found that to some extent, the generation of knowledge stickiness can be avoided by knowledge characteristics, learning intention, resource attraction, and partnership. Huan et al. [24] pointed out that the influencing factors of knowledge stickiness are transfer intention, transfer ability, knowledge base, knowledge characteristics, and receiving ability.

Based on the collaborative innovation environment of IUR, this study mainly discusses the knowledge stickiness with its own research characteristics. The theoretical model of knowledge stickiness elements of IUR is proposed to enhance the pertinence and rationality of the indicators in the specific context and to form a systematic, comprehensive, reasonable, and specific variable that affects knowledge stickiness. This study holds that the knowledge transfer in IUR is mainly affected by the factors of knowledge sender (university-research party), knowledge receiver (industry party), cognitive structure difference, knowledge characteristics, and relationship between IUR. Based on S-A-C theory, knowledge stickiness generated in IUR is divided into cognitive stickiness layer [25-27]; Easterby-Smith et al., 2008), activity stickiness layer, and situational stickiness layer [28].

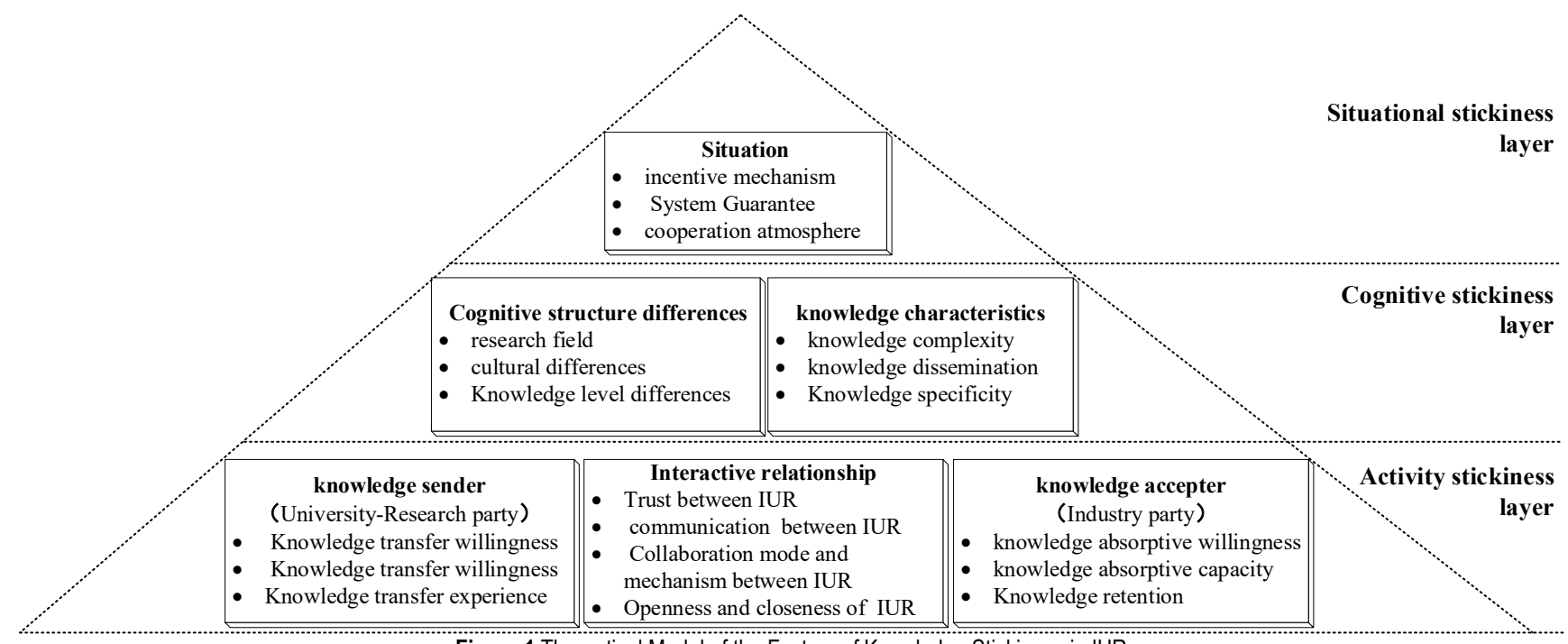

Figure 1 Theoretical Model of the Factors of Knowledge Stickiness in IUR

\subsection{Formation Process of Knowledge Stickiness}

Knowledge has become the most strategic resource for enterprises [29-31]. Under the background of knowledge modularization and labor division [32], enterprises constantly seek cooperation with universities and scientific research institutes to provide competitive advantages for their technological innovation and development [33, 34]. However, due to the exchange, sharing, and transfer of knowledge, transferring knowledge among the subjects of IUR is difficult. Such difficulty is affected by the characteristics of knowledge (complexity, specificity, embeddedness, being tacit) and the interaction between IUR, which increases the uncertainty of knowledge transfer and absorption, resulting in knowledge stickiness [35-37].

The collaborative innovation between IUR promotes the integration of resources and technology across fields, industries, disciplines, and departments on the basis of benefit sharing and risk sharing. From the perspective of knowledge transfer, the process of collaborative innovation between IUR is the process of knowledge startup (forming collaborative will), knowledge implementation (knowledge resource flow and focus), knowledge adjustment (knowledge sharing and interaction), and knowledge integration (knowledge creation and application).

(1) Initiation phase

Recognizing that the demand for knowledge collaboration is available among IUR, the subjects of IUR will first study the market economy situation from a macro perspective. Then, they will analyze its feasibility from a micro perspective to determine whether to implement the collaboration strategic layout of IUR [38]. When the collaborative will is formed, each subject in the IUR will start to transfer knowledge and generate knowledge stickiness. Owing to the evident knowledge gap between IUR and the immaturity of operation mechanism of knowledge transfer, completing knowledge transfer in the early stage of cooperation is difficult.

(2) Implementation phase

Each subject of IUR enters the phase of knowledge resource flow and focuses after forming the collaborative will. At this time, the flow of IUR begins to transform from a single level of internal flow into a multi-level interactive flow (as shown in Fig. 2). Owing to the established 
cooperation among the subjects of IUR in a virtual organization [39] during the specific implementation stage, differences in objectives and concepts will be inevitable. In addition, the research fields between IUR are different, and their knowledge levels are different from one other. Thus, intangible knowledge that is difficult to express and code will be difficult to be transferred. The main goal of collaboration between industry-university-research at this phase is to reduce the stickiness of knowledge by exploring the appropriate cooperation mode in the specific cooperation [40].

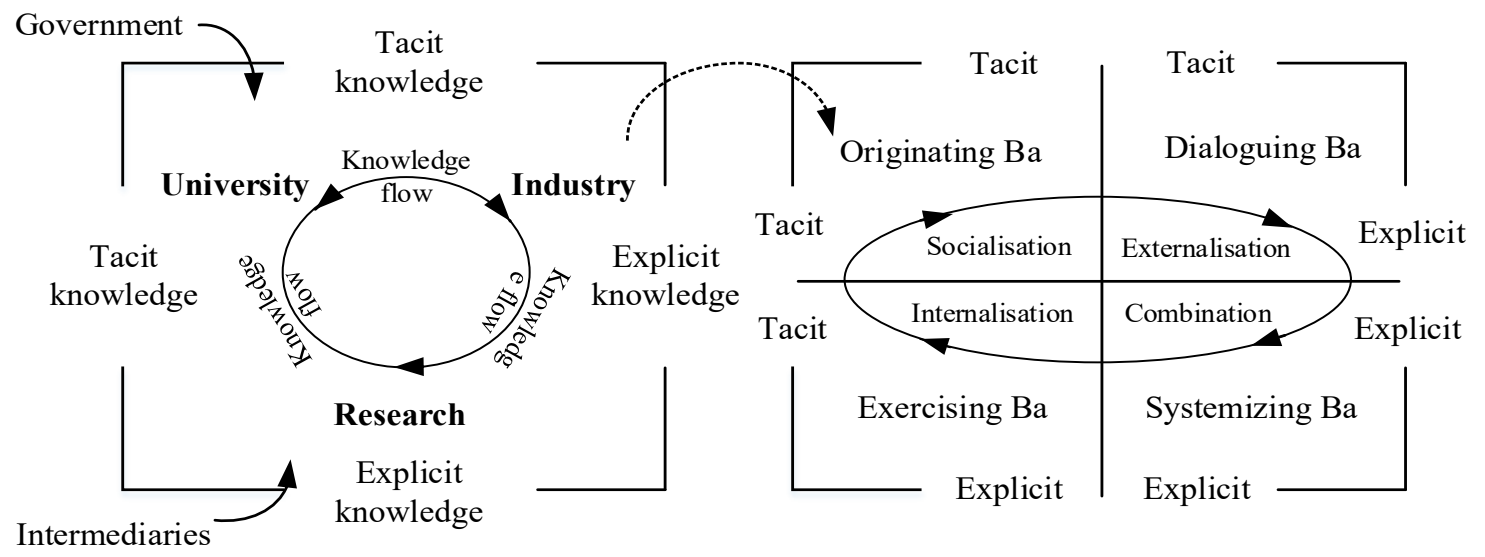

Figure 2 Knowledge Flow Process in Collaborative Innovation of IUR

(3) Adjustment phase

The knowledge receiver (enterprise) needs to adjust the received knowledge to meet the needs of specific environment and people when the knowledge begins to enter the state of steady sharing and interaction. A weak willingness of the knowledge receiver to absorb and a low ability to maintain received knowledge will greatly reduce transfer efficiency. If the knowledge receiver simply mechanically copies the original knowledge and lacks the ability to adjust and create new knowledge, the transferred knowledge will not adapt to the new organizational environment, and the utilization rate of knowledge transformation will be reduced, which is not conducive to knowledge creation. The purpose of the adjustment phase is to accelerate the knowledge appreciation in the process of knowledge transfer, knowledge application, and knowledge innovation.

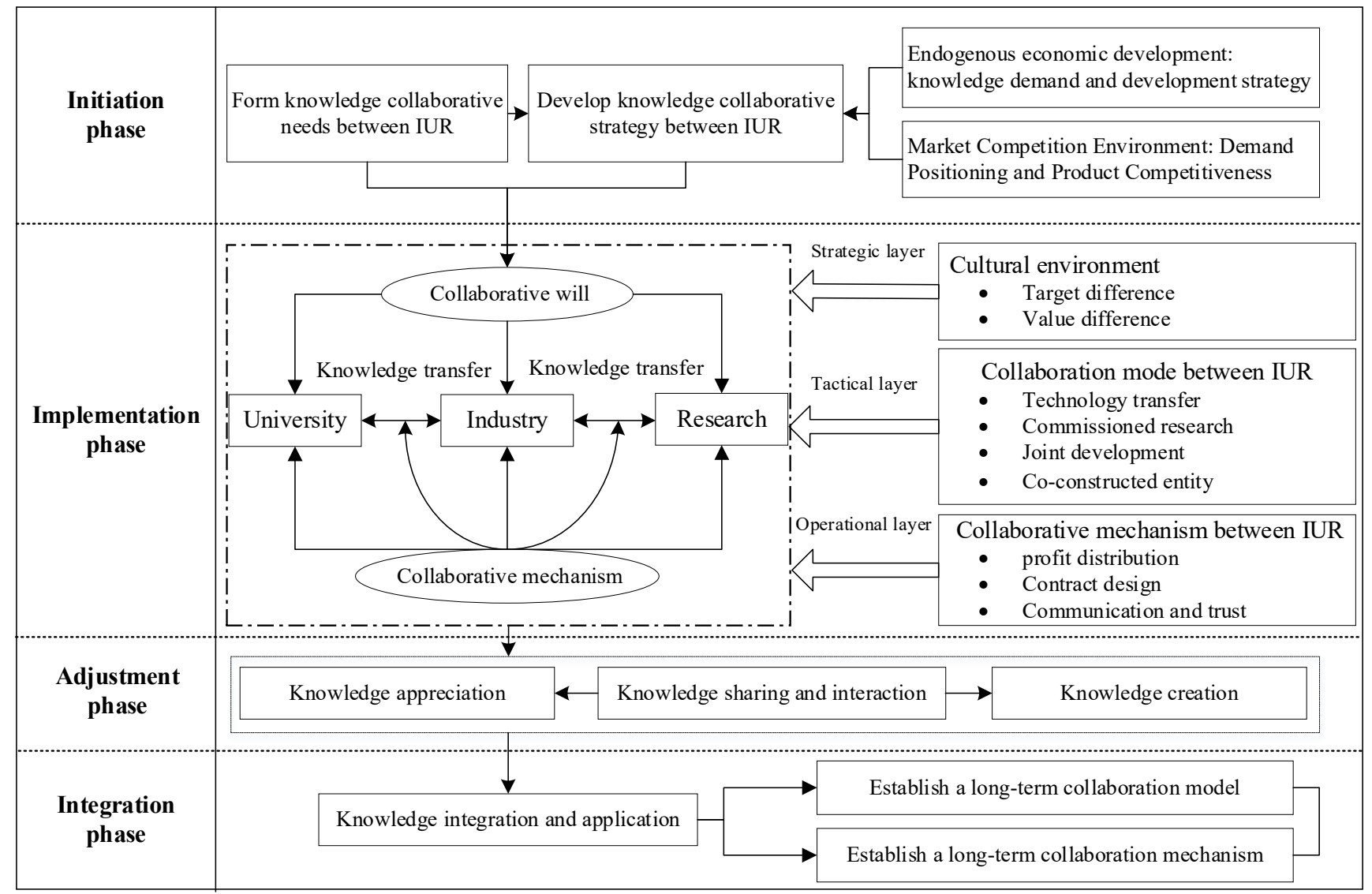

Figure 3 Knowledge Transfer Process in Collaborative Innovation of IUR 


\section{(4) Integration phase}

In addition to the knowledge transfer process of knowledge carrier, the collaboration of IUR is also a process of forming new knowledge through knowledge fusion [41]. The process of knowledge creation is the premise of the collaborative innovation and steady operation of IUR. However, as the newly created knowledge has just formed at the beginning of integration, new knowledge stickiness may arise [42]. Therefore, integration aims to effectively resist the impact caused by the changes of knowledge subject, object, and policy environment by establishing a long-term collaborative innovation mode and operation mechanism, combining knowledge sharing and knowledge creation (as shown in Fig. 3).

\section{METHODOLOGY \\ 3.1 Modelling}

To ensure that the relationship between factors in collaborative innovation of IUR and knowledge stickiness can be further reflected, this study puts forward the analysis framework of knowledge stickiness in collaborative innovation of IUR. This study also analyzes the basic hypothesis that the factors influencing knowledge stickiness between IUR are mainly activity stickiness, cognitive stickiness, and situational stickiness, namely, $E=$ $f(C, W, Q)$. Where $E$ represents total knowledge stickiness, $C$ represents cognitive layer knowledge stickiness, $W$ represents activity layer knowledge stickiness, and $Q$ represents situation stickiness.

(1) Cognitive layer knowledge stickiness

Cognition stickiness layer includes the cognitive factor $(S)$ and the knowledge characteristic factor $(K)$, that is, $C=$ $f(S, K)$.

Cognitive factors. The form of inner product can be used to express the cognitive differences caused by different knowledge backgrounds. Hence, the following cognitive factor influence function can be constructed:

$$
\left\{\begin{array}{l}
S=s_{i} \cdot s_{j}=\left|s_{i}\right| \cdot\left|s_{j}\right| \cdot \cos \theta_{i j} \quad \theta_{i j} \in\left(0, \frac{\pi}{2}\right), i \neq j \\
i=1,2, \ldots, n \\
j=1,2, \ldots, n
\end{array}\right.
$$

where $s_{i}$ represents the knowledge vector of universityresearch party, $s_{j}$ represents the knowledge vector of industry party, and $\theta_{i j}$ is defined as the difference degree of knowledge cognition, especially when $\theta_{i j}=\pi / 2$, no knowledge exchange occurs between IUR.

Knowledge is characterized by complexity, recessiveness, and exclusiveness (represented by $W_{1}, W_{2}$, $W_{3}$, respectively, $\left.W_{i} \in[0,1] ; i=1,2,3\right)$. The closer the value of $W_{i}$ is to 0 , the less complex the knowledge is. The closer the value of $W_{i}$, the more complex it is. According to the characteristics of knowledge, the influence function of knowledge characteristics factors can be constructed as follows:

$$
K=\frac{M A X\left(W_{1}, W_{2}, W_{3}\right)}{1+\exp \left(X^{-1}\right)}
$$

\section{(2) Activity stickiness layer}

Activity stickiness layer includes three levels: university-research party (knowledge sender), industry party (knowledge receiver), and the relationship between IUR. To ensure that the relationship of activity stickiness layer can be fully revealed, this study assumes a mutual symbiotic relationship between knowledge subjects, the knowledge transfer between IUR is carried out under mutual symbiosis, and knowledge stickiness is affected by itself and the other party.

Universities and scientific research institutes provide new knowledge (variable is set as $U(t)$ ), enterprises accept new knowledge to complete the transformation of scientific and technological achievements (variable is set as $F(t)$ ), and the main quality parameter is the output of each knowledge subject of IUR. Based on the fact that all essential productive factors are constant, a superior limit boundary exists between the university-research party and the industry party. The saturation quantity is $\bar{U}, \bar{F}$. To assume that the natural growth rate of output between IUR is $r_{1}, r_{2}$, the logistic growth equation among knowledge subjects of IUR is as follows:

$$
\left\{\begin{array}{l}
\frac{\mathrm{d} U(t)}{\mathrm{d} t}=r_{1} U_{0}(t)\left(1-\frac{U(t)}{\bar{U}}\right) \\
\frac{\mathrm{d} F(t)}{\mathrm{d} t}=r_{2} F_{0}(t)\left(1-\frac{F(t)}{\bar{F}}\right)
\end{array}\right.
$$

Among them:

$1-U(t) / \bar{U}$ represents the stickiness factor of the university-research party.

$1-F(t) / \bar{F}$ represents the stickiness factor of the industry party.

In view of the mutual symbiotic relationship between the subjects of IUR, the university-research party will create knowledge according to the requirements of the industry party to promote the transformation of the scientific and technological achievements of the industry party. Moreover, the industry party will also have corresponding incentive effect on the knowledge creation of the university-research party. That is, the universityresearch party will gain economic reward and nonmonetary welfare (such as enhanced reputation) when the industry party realizes the commercialization of achievements. The logistic symbiosis model under the symbiosis model can be obtained:

$$
\left\{\begin{array}{l}
\frac{\mathrm{d} U(t)}{\mathrm{d} t}=r_{1} U_{0}(t)\left(1-\frac{U(t)}{\bar{U}}+\alpha \frac{F(t)}{\bar{F}}\right) \\
\frac{\mathrm{d} F(t)}{\mathrm{d} t}=r_{2} F_{0}(t)\left(1-\frac{F(t)}{\bar{F}}+\beta \frac{U(t)}{\bar{U}}\right)
\end{array}\right.
$$

Among them, $\alpha$ represents the symbiotic contribution rate of the industry party to the university-research party, which refers to the impact of the transformation of the 
scientific and technological achievements of the industry party on the knowledge creation of the university-research party. $\beta$ represents the symbiotic contribution rate of the university-research party to the industry party, which refers to the contribution of the university-research party to the transformation of the scientific and technological achievements of the industry party in the process of knowledge sharing.

The conclusion that the activity stickiness layer is mainly affected by the stickiness factors of the universityresearch party and the industry party under the symbiotic environment can be drawn through the logistic symbiotic model.

(3) Situational stickiness layer

Situational stickiness layer includes the influence of incentive mechanism $a(t)$, institutional guarantee $b(t)$, and cooperation atmosphere $R d(t)$ on knowledge stickiness. In this study, the linear influence function of situational stickiness expresses the influence of incentive mechanism, system guarantee, and cooperation atmosphere on knowledge stickiness.

$$
Q(t, u, \sigma)=\frac{M A X(a(t), b(t), R d(t))}{\|a(t), b(t), R d(t)\|} \|\left.\boldsymbol{x}\right|_{2}=\left(\sum_{i=1}^{n} x_{i}^{2}\right)^{\frac{1}{2}}
$$

\subsection{Evolution}

In essence, the process of knowledge transfer is the process of knowledge flow caused by knowledge potential difference. That is, high potential knowledge will gradually transfer to low potential knowledge with the change of time, which is similar to the process of temperature changing with time in heat conduction. In Fourier's Law, heat flow $Q$ is directly proportional to the temperature gradient $\mathrm{d} T / \mathrm{d} z$ and the cross-sectional area $A$ (that is, $Q=-k . \mathrm{d} T / \mathrm{d} z . A, k$ is the coefficient of heat conduction), and the generation of heat conduction of (between) objects requires the following conditions:

(1) Temperature gradient exists between objects. This condition is basic for heat conduction and determines the direction of heat conduction. Owing to the potential difference in the process of knowledge transfer, the high potential knowledge of the university-research party will gradually transfer to the industry party; thus, knowledge gradient and clear transfer direction will be generated, which conforms to the condition of heat conduction.

(2) The coefficient of heat conductivity. In heat conduction, the coefficient of heat conductivity is the main factor affecting the speed and intensity of heat transfer. Knowledge stickiness will be caused by the blocking effect in the process of knowledge transfer. The degree of knowledge stickiness will also affect the speed and intensity of knowledge transfer, which conforms to the condition of heat conduction.

(3) Cross-sectional area. The cross-sectional area of heat conduction is the heat transfer area, which is an important factor affecting the conduction effect. Communication channels also have an impact on knowledge transfer. In general, the smoother the channel of knowledge communication is, the faster the knowledge transmission. Additionally, the final effect of knowledge transmission is related to the knowledge distance between the two mechanisms, which conforms to the condition of heat conduction.

This study ensures that the influence of knowledge stickiness in the collaborative innovation of IUR on knowledge transfer can be dynamically reflected. Hence, the knowledge flow process is dynamically evolved based on heat conduction theory, and the knowledge quantity and heat are compared to achieve the distribution of knowledge field in a stable state. That is, the following deterministic problems are solved:

$$
\left\{\begin{array}{l}
a^{2}\left[\frac{\partial^{2} u(x, y)}{\partial x^{2}}+\frac{\partial^{2} u(x, y)}{\partial y^{2}}\right]=0 \\
\text { Value range } \quad: 0 \leq \mathrm{x} \leq 1,0 \leq \mathrm{y} \leq 1 \\
\text { Initial conditions } \quad: u(x, y)=0 \\
\text { Boundary conditions: }\left.u(x, y)\right|_{y=0}=0,\left.u(x, y)\right|_{0.8>y>0.2}=-3 \\
\qquad\left.u(x, y)\right|_{y=0}=0,\left.u(x, y)\right|_{0.8>y>0.2}=-3
\end{array}\right.
$$

$u(x, y) \mid$ is the temperature of knowledge. It is assumed that the initial temperature of the industry party is -3 , and that of the university-research party is 0 . The area of the industry party is $0.8>y>0.2,0.8>x>0.2$. In the $a^{2}=k / c \rho$, $k$ is the coefficient of heat conductivity of the object. $k$ is compared to the coefficient of knowledge conduction, $c$ is the rate of knowledge heating, and $\rho$ is the density of knowledge.

Among them, $E=1 / k$, that is, the reciprocal of knowledge stickiness is assumed to be the coefficient of knowledge conduction.

The method of separating variables is used to solve the special solution which satisfies the boundary conditions and is in the form of separated variables. Suppose $u(x, y)=$ $X(x) Y(y)$, and substitute it into the problem of definite solution to yield:

$$
X^{\prime \prime}(x) Y(y)+X(x) Y^{\prime \prime}(y)=0 \text { or } \frac{X^{\prime \prime}(x)}{X(x)}=-\frac{Y^{\prime \prime}(y)}{Y(y)}
$$

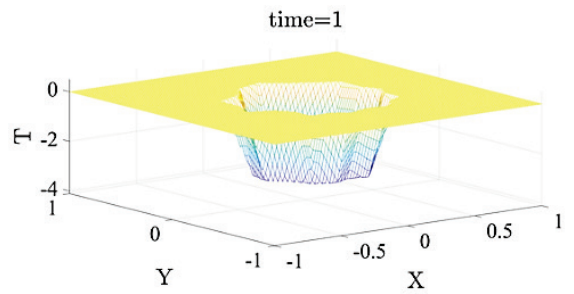

(a)

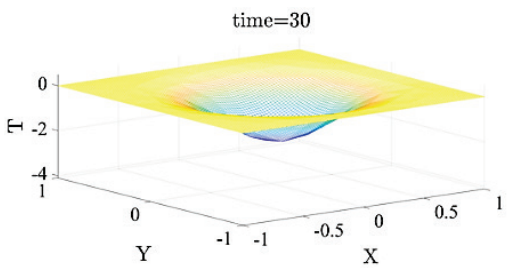

(b)

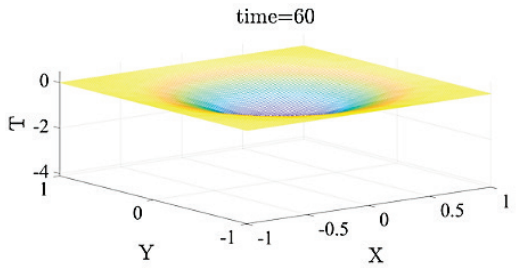

(c) 


\section{RESULT ANALYSIS AND DISCUSSION}

MATLAB software was used to carry out the simulation experiment on the knowledge transfer (propagation) model of heat conduction. The initial knowledge temperature of the university-research party is set as 0 (four sides area), and the initial temperature of the industry party is set as -3 (middle area), which is used to represent the knowledge potential difference between the subjects of IUR. In this study, the knowledge temperature of the university-research party is set as a constant value because the knowledge of the university-research party will not decrease in the process of transfer (unlike the gradual decrease of temperature in heat conduction).

In the process of simulation evolution (see Figs. $4 \mathrm{a}, 4 \mathrm{~b}$ and $4 \mathrm{c}$ ), the amount of knowledge of the industry party increases with the change of time and finally approaches the amount of knowledge of the university-research party. This finding shows that not only the knowledge difference between IUR will become increasingly small; the knowledge stickiness will also become smaller through continuous cooperation, communication, and exploration. It meets the development law of the cooperation between IUR in real life; the process of knowledge transfer is the process of knowledge appreciation and knowledge creation.

\subsection{Knowledge Stickiness and Knowledge Quantity}

In this study, the influence of different stickiness on knowledge transfer is analyzed. Through the simulation experiment, this study finds that the knowledge stickiness of cognitive layer (Fig. 5a) and situational layer (Fig. 5b) has a direct impact on the efficiency of knowledge transfer. The greater the knowledge stickiness, the slower the knowledge transfer and the less knowledge stickiness, the faster knowledge transfer. Therefore, identifying the factors that affect the knowledge stickiness of IUR and taking practical control measures will greatly improve the performance of knowledge transfer and achieve cooperative innovation.

The simulation trends of knowledge stickiness in cognitive layer and situational layer are compared in the study. Knowledge stickiness in cognitive layer has a steep effect on knowledge transmission, showing that knowledge stickiness at the cognitive level has an evident impact on knowledge transfer and is the primary consideration of management and control. In addition, knowledge stickiness is more sensitive to the situation level after comparing with different knowledge stickiness coefficients, showing that the knowledge stickiness effect can be changed rapidly by optimizing the situation level environment.

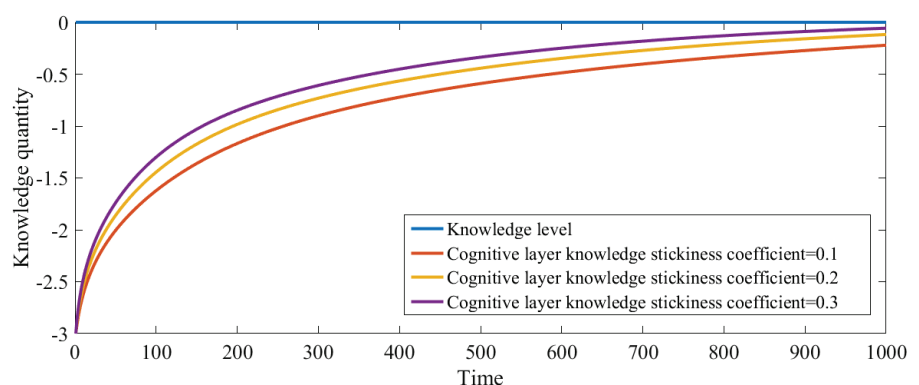

(a)

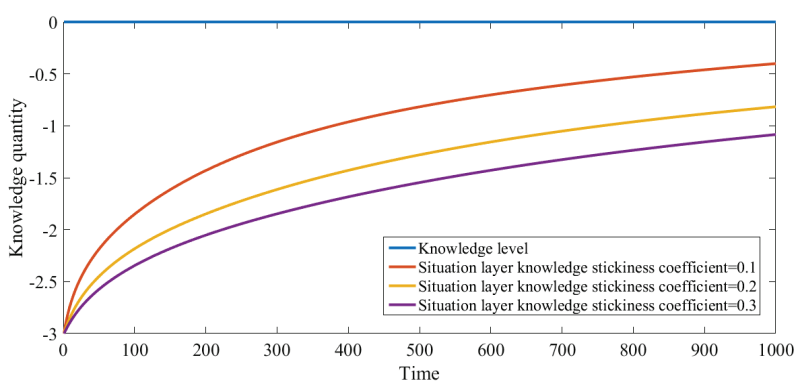

(b)

Figure 5 Evolution Process of Knowledge Stickiness and Knowledge Quantity

\subsection{Knowledge Stickiness and Collaborative Innovation}

Fig. 6a shows that the total knowledge stickiness (situational stickiness layer) decreases with time. The figure shows a trend of changing from rapid to gentle and finally to zero, indicating that creating a good collaborative situation in the early stage of knowledge transfer is an effective measure to reduce knowledge stickiness. Moreover, this study focuses on the simulation experiment of the relationship between cooperation atmosphere and knowledge stickiness to reflect the internal relationship of context layer, finds the inverse relationship between

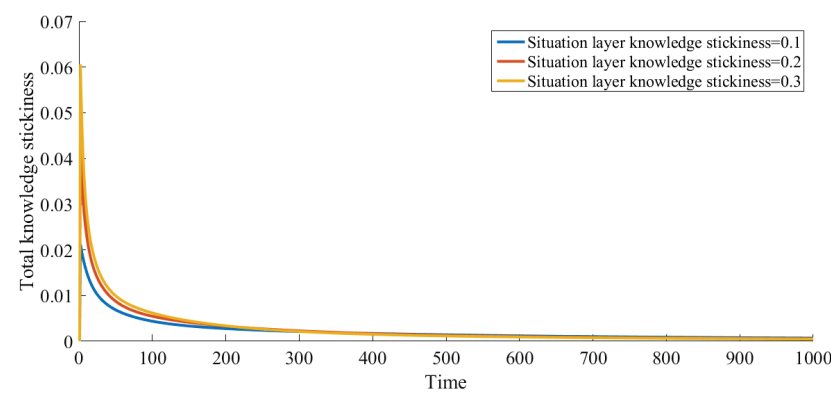

(a) knowledge stickiness and cooperation atmosphere, and finds an important turning point of 0.2 . Knowledge stickiness changes rapidly when the cooperation atmosphere is less than 0.2 , and gradually slows down when the cooperation atmosphere is greater than 0.2 . These changes show that knowledge stickiness effect is smaller in a collaborative innovation cooperation environment. To reduce the knowledge stickiness effect, the cooperation atmosphere should at least reach a basic standard so that the influence of cooperation atmosphere on knowledge stickiness can be reduced.

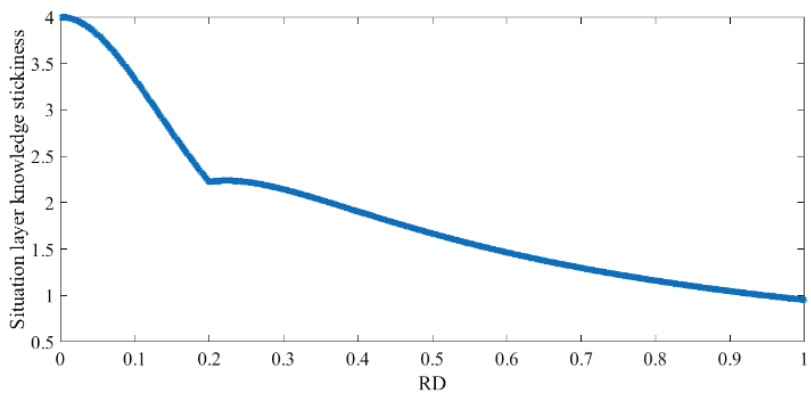

(b)

Figure 6 Evolution Process of Knowledge Stickiness and Collaborative Situation 


\section{CONCLUSIONS}

This study aims to explore the cause and mechanism of knowledge stickiness in the collaborative innovation of IUR from the perspective of knowledge stickiness in knowledge transfer of IUR. This study also aims to find management and control suggestions to reduce knowledge stickiness. Through systematic analysis and dynamic simulation of the evolution process and law of knowledge transfer stickiness, the following conclusions can be made:

(1) Factors such as the university-research party, the industry party, cognitive structure differences, knowledge characteristics, relationship between industry-universityresearch, and situation have impacts on knowledge stickiness among subjects. The process of knowledge transfer is the process of initiating, implementing, adjusting, and integrating knowledge.

(2) The process of knowledge transfer between IUR is the process of knowledge increment and knowledge creation, and the process of knowledge quantity evolution between IUR is the process of continuous approximation between the industry party and the university-research party. The knowledge of the university-research party is learned and used by the industry party constantly to deepen its thinking and improve its ability, and the universityresearch party accumulates practical experience through the feedback of the enterprise.

(3) Knowledge stickiness has a direct impact on the efficiency of knowledge transfer. The effect of cognitive stickiness is more evident than that of situational stickiness Compared with the cognitive stickiness layer, stickiness coefficient of different situations has significantly different effects on the knowledge quantity.

(4) The degree of knowledge stickiness is inversely proportional to the cooperation atmosphere and the situation, showing that the stickiness effect of knowledge can be effectively weakened by creating a good collaborative innovation environment.

The following enlightenment on recognizing knowledge management in collaborative environment and weakening the knowledge stickiness effect in practice can be provided by the following conclusions:

(1) The system and situation of collaborative innovation of IUR should be created. The science and technology policy of IUR should be improved, the driving force of the government should be fully exerted, the reform of IUR system and the innovation of science and technology system should be deepened, and the innovation subject position of enterprises in the cooperation system of IUR should be strengthened to truly form the risk sharing mechanism of "benefit sharing, risk sharing, and collaborative development".

(2) The knowledge sharing mechanism of collaborative innovation of IUR should be established. First, the knowledge information exchange platform should be established by using modern network information technology. Second, the conflicts among the subjects of IUR should be minimized by expanding communication channels. Finally, learning organizations should be established to understand their knowledge background and improve their willingness and ability of knowledge transfer.

Our study suggests several promising opportunities in future study. First, the influencing factors are mainly discussed from the subjective and objective perspective of knowledge stickiness between IUR, whereas the role of innovation network nodes in the process is ignored and the dimensions of influencing factors are not comprehensive enough. In addition, the knowledge transmission model based on heat conduction theory lacks practical verification, which needs to be supported by specific cases in reality. Finally, expanding the study on knowledge stickiness between IUR is necessary to provide reference for knowledge management (transfer and sharing) in China.

\section{Acknowledgements}

This work was supported by the Humanities and Social Sciences Foundation of the Chinese Ministry of Education (No: 19YJAZH055).

\section{REFERENCES}

[1] Lee, R., Lee, J. H., \& Garrett, T. C. (2019). Synergy effects of innovation on firm performance. Journal of Business Research, 99, 507-515. https://doi.org/10.1016/j.jbusres.2017.08.032

[2] Baldwin, C. \& Von Hippel, E. (2011). Modeling a paradigm shift: From producer innovation to user and open collaborative innovation. Organization Science, 22(6), 13991417. https://doi.org/10.1287/orsc. 1100.0618

[3] Swink, M. (2006). Building collaborative innovation capability. Research-Technology Management, 49(2), 3747. https://doi.org/10.1080/08956308.2006.11657367

[4] Ketchen Jr, D. J., Ireland, R. D., \& Snow, C. C. (2007). Strategic entrepreneurship, collaborative innovation, and wealth creation. Strategic Entrepreneurship Journal, 1(3-4), 371-385. https://doi.org/10.1002/sej.20

[5] Perkmann, M. \& Walsh, K. (2007). University-industry relationships and open innovation: Towards a research agenda. International Journal of Management Reviews, 9(4), 259-280. https://doi.org/10.1111/j.1468-2370.2007.00225.x

[6] Liu, G., Ye, J., \& Argyres, C. (2020). Modeling and simulation of the knowledge growth process among new energy technology firms in the distributed innovation network. DYNA, 95(1), 54-60.

[7] Sørensen, E. \& Torfing, J. (2011). Enhancing collaborative innovation in the public sector. Administration \& Society, 43(8), 842-868. https://doi.org/10.1177/0095399711418768

[8] Kalling, T. (2003). Organization-internal transfer of knowledge and the role of motivation: a qualitative case study. Knowledge and Process Management, 10(2), 115126. https://doi.org/10.1002/kpm.170

[9] Attewell, P. (1992). Technology diffusion and organizational learning: The case of business computing. Organization Science, 3(1), 1-19. https://doi.org/10.1287/orsc.3.1.1

[10] Von Hippel, E. (1994). "Sticky information" and the locus of problem solving: implications for innovation. Management Science, 40(4), 429-439. https://doi.org/10.1287/mnsc.40.4.429

[11] Buntak, K., Kovačić, M., \& Mutavdžija, M. (2019). Internet of things and smart warehouses as the future of logistics. Tehnički Glasnik, 13(3), 248-253. https://doi.org/10.31803/tg-20190215200430

[12] Bodolica, V., Dupuis, D., \& Spraggon, M. (2020). At the intersection of corporate governance and performance in family business settings: Extant knowledge and future research. Business Ethics: A European Review, 29(1), 143166. https://doi.org/10.1111/beer.12254

[13] Siegel, D. S., Waldman, D. A., Atwater, L. E., \& Link, A. N. (2003). Commercial knowledge transfers from universities to firms: improving the effectiveness of university-industry 
collaboration. The Journal of High Technology Management Research, 14(1), 111-133. https://doi.org/10.1016/S1047-8310(03)00007-5

[14] Szulanski, G. (1996). Exploring internal stickiness: Impediments to the transfer of best practice within the firm. Strategic Management Journal, 17(S2), 27-43. https://doi.org/10.1002/smj.4250171105

[15] Simonin, B. L. (1999). Ambiguity and the process of knowledge transfer in strategic alliances. Strategic Management Journal, 20(7), 595-623. https://doi.org/10.1002/(SICI)1097-0266(199907)20:7<595::AIDSMJ47>3.0.CO;2-5

[16] Riusala, K. \& Smale, A. (2007). Predicting stickiness factors in the international transfer of knowledge through expatriates. International Studies of Management\&Organization, 37(3), 16-43. https://doi.org/10.2753/IMO0020-8825370301

[17] Li, C. Y. \& Hsieh, C. T. (2009). The impact of knowledge stickiness on knowledge transfer implementation, internalization, and satisfaction for multinational corporations. International Journal of Information Management, 29(6), 425-435. https://doi.org/10.1016/j.jijinfomgt.2009.06.004

[18] Pfajfar, D. \& Santoro, E. (2010). Heterogeneity, learning and information stickiness in inflation expectations. Journal of Economic Behavior\& Organization, 75(3), 426-444. https://doi.org/10.1016/j.jebo.2010.05.012

[19] Smale, A. (2008). Global HRM integration: a knowledge transfer perspective. Personnel Review, 37(2), 145-164. https://doi.org/10.1108/00483480810850515

[20] Carmi, N., Arnon, S., \& Orion, N. (2015). Transforming environmental knowledge into behavior: The mediating role of environmental emotions. The Journal of Environmental Education, 46(3), 183-201. https://doi.org/10.1080/00958964.2015.1028517

[21] Szulanski, G. (2000). The process of knowledge transfer: A diachronic analysis of stickiness. Organizational Behaviorand Human Decision Processes, 82(1), 9-27. https://doi.org/10.1006/obhd.2000.2884

[22] Cummings, J. L. \& Teng, B. S. (2003). Transferring R\&D knowledge: the key factors affecting knowledge transfer success. Journal of Engineering and Technology Management, 20(1-2), 39-68. https://doi.org/10.1016/S0923-4748(03)00004-3

[23] Pérez - Nordtvedt, L., Kedia, B. L., Datta, D. K., \& Rasheed, A. A. (2008). Effectiveness and efficiency of cross-border knowledge transfer: An empirical examination. Journal of Management Studies, 45(4), 714-744. https://doi.org/10.1111/j.1467-6486.2008.00767.x

[24] Huan, H., Yongyuan, M., Sheng, Z., \& Qinchao, D. (2017). Characteristics of knowledge, people engaged in knowledge transfer and knowledge stickiness: Evidence from Chinese R\&D team. Journal of Knowledge Management, 21(6), 1559-1579. https://doi.org/10.1108/JKM-02-2017-0054

[25] Bhagat, R. S., Kedia, B. L., Harveston, P. D., \& Triandis, H. C. (2002). Cultural variations in the cross-border transfer of organizational knowledge: An integrative framework. Academy of Management Review, 27(2), 204-221. https://doi.org/10.5465/amr.2002.6588000

[26] De Luca, L. M. \& Atuahene-Gima, K. (2007). Market knowledge dimensions and cross-functional collaboration: Examining the different routes to product innovation performance. Journal of Marketing, 71(1), 95-112. https://doi.org/10.1509/jmkg.71.1.095

[27] Easterby-Smith, M., Lyles, M. A., \& Tsang, E. W. (2008). Inter-organizational knowledge transfer: Current themes and future prospects. Journal of Management Studies, 45(4), 677-690. https://doi.org/10.1111/j.1467-6486.2008.00773.x
[28] Luo, S. H. \& Lee, G. G. (2015). Exploring the key factors to successful knowledge transfer. Total Quality Management \& Business Excellence, 26(3-4), 445-464. https://doi.org/10.1080/14783363.2013.856548

[29] Nonaka, I. (1994). A dynamic theory of organizational knowledge creation. Organization Science, 5(1), 14-37. https://doi.org/10.1287/orsc.5.1.14

[30] Grant, R. M. (1996). Toward a knowledge - based theory of the firm. Strategic Management Journal, 17(S2), 109-122. https://doi.org/10.1002/smj.4250171110

[31] Quevedo-Blasco, R. \& Buela-Casal, G. (2017). Influence of the implementation of the European higher education area on engineering and architecture university teachers. DYNA, 92(3), 333-338.

[32] Zhang, S., Yuan, C., \& Wang, Y. (2019). The impact of Industry-University-Research alliance portfolio diversity on firm innovation: Evidence from Chinese manufacturing firms. Sustainability, 11(8), 2321. https://doi.org/10.3390/su11082321

[33] Jensen, R. \& Szulanski, G. (2004). Stickiness and the adaptation of organizational practices in cross-border knowledge transfers. Journal of International Business Studies, 35(6), 508-523. https://doi.org/10.1057/palgrave.jibs.8400107

[34] Buganza, T. \&Verganti, R. (2009). Open innovation process to inbound knowledge. European Journal of Innovation Management, 12(3), 306-325. https://doi.org/10.1108/14601060910974200

[35] Szulanski, G., Ringov, D., \& Jensen, R. J. (2016). Overcoming stickiness: How the timing of knowledge transfer methods affects transfer difficulty. Organization Science, 27(2), 304-322. https://doi.org/10.1287/orsc.2016.1049

[36] Wang, S., Wang, J., Xu, Q., \& Zhu, Y. (2019). Rival absorptive capacity and innovation performance of an enterprise: the moderating effect of dual appropriability mechanisms. Transformations in Business \& Economics, 18(3), 565-579.

[37] Safari, A., Salehzadeh, R., Panahi, R., \& Abolghasemian, S. (2018). Multiple pathways linking environmental knowledge and awareness to employees' green behavior. Corporate Governance: The International Journal of Business in Society, 18(1), 81-103. https://doi.org/10.1108/CG-08-2016-0168

[38] Jin, G. Y. (2013). On Synergy of Management Innovation and Technological Innovation of Enterprise, University and Research. Applied Mechanics and Materials, 291, 29682977. https://doi.org/10.4028/www.scientific.net/AMM.291-294.2968

[39] Gao, S., Guo, Y., Chen, J., \& Li, L. (2016). Factors affecting the performance of knowledge collaboration in virtual team based on capital appreciation. Information Technology and Management, 17(2), 119-131. https://doi.org/10.1007/s10799-015-0248-y

[40] Nonaka, I., Toyama, R., \& Konno, N. (2000). SECI, Ba and leadership: a unified model of dynamic knowledge creation. Long Range Planning, 33(1), 5-34. https://doi.org/10.1016/S0024-6301(99)00115-6

[41] Harjoto, M. A., Laksmana, I., \& Wen Yang, Y. (2019). Board nationality and educational background diversity and corporate social performance. Corporate Governance: The International Journal of Business in Society, 19(2), 217-239. https://doi.org/10.1108/CG-04-2018-0138

[42] Pan, X., Chen, X., Guo, H., \& Zhang, Y (2020). One size doesn't fit all: How institutional complexity within the state shapes firms' environmental innovation. Business Ethics: A European Review. https://doi.org/10.1111/beer.12280 


\section{Contact information:}

Feng ZHANG, PhD candidate

School of Management, Wuhan University of Technology,

Room 522, School of Management, Wuhan University of Technology,

No.122 Luoshi Road, 430070, Wuhan, Hubei Province, P. R. China

E-mail: zhangfeng@whut.edu.cn

Guoxin LIU, PhD, Professor

(Corresponding author)

School of Management, Wuhan University of Technology,

Room 522, School of Management, Wuhan University of Technology,

No.122 Luoshi Road, 430070, Wuhan, Hubei Province, P. R. China

E-mail: syliuguox@126.com

Yu WU, PhD, Lecturer

School of Economics, Henan University of Science and Technology,

Room 725, School of Economics, Henan University of Science and Technology,

No.263 Kaiyuan Avenue , 471023, Luoyang, Henan Province, P. R. China

E-mail: meiyouyu1987@sina.com 